\title{
In tyrannos! \\ Teología política y «diferencia mesiánica» en el nuevo pensamiento de Franz Rosenzweig
}

\author{
In tyrannos! \\ Political Theology and "messianic difference" in \\ Franz Rosenzweig's New Thinking
}

\author{
Roberto NAVARrete AlONSO \\ The Franz Rosenzweig Minerva Research Center - The Hebrew University of Jerusalem
}

Recibido: 14-01-2015

Aceptado: 25-08-2015

\section{Resumen}

El presente artículo tiene como objeto una elucidación del significado teológico-político de la concepción relacional del tiempo tematizada por Franz Rosenzweig en La estrella de la redención, cuya singularidad quiere expresar aquí el concepto «diferencia mesiánica». Enmarcada en la querella de la secularización, esta temporalidad mesiánica representa una respuesta a la verificación de la articulación hegeliana de filosofía política y filosofía de la historia que, según Rosenzweig, tuvo lugar a través de la Primera Guerra Mundial. El consiguiente desengaño político sufrido por el autor de Hegel und der Staat condujo a éste a la búsqueda de un nuevo pensamiento cuya novedad viene dada por el primado ontológico del tiempo y por la indisoluble relación establecida por Rosenzweig entre «temporalidad» $\mathrm{y}$ «alteridad». Tomando como punto de partida la distinción Rosenzweiguiana entre «personalidad» y «sí-mismo», es decir, entre «ética»y «metaética», el final del trabajo explora los diversos modos en que se temporaliza el sí-mismo en función de sus relaciones con las temporalizaciones de Dios y mundo, así como sus correspondientes efectos de carácter teológico-político.

Palabras clave: diferencia mesiánica, Franz Rosenzweig, teología política, secularización. 


\begin{abstract}
This paper deals with an elucidation of the theologico-political implications of Franz Rosenzweig's relational conception of time in his work The Star of Redemption, the peculiarity of which expresses the concept "messianic difference". Considered from the standpoint of the secularization debate, this messianic temporality offers a response to the verification of the Hegelian assembly of political philosophy and philosophy of history which, according to Rosenzweig, First World War represented. The consequent political disappointment experienced by the author of Hegel und der Staat led him to the pursuit of a Neues Denken determined by the ontological primacy of time as well as the unbreakable relationship which Rosenzweig established between "temporality" and "otherness". Taking as terminus a quo the anthropological distinction between "personality" and "self", i. e. between "ethics" and "metaethics", that Rosenzweig presents in The Star, I will finally attempt to explore the various modes of temporalization that, depending on the relation to the temporalization of God and the world, are possible for the Rosenzweigian Self, as well as their related theologico-political aftermaths.
\end{abstract}

Keywords: Franz Rosenzweig, messianic difference, political theology, secularization.

El presente trabajo pretende arrojar luz sobre el significado teológico-político de la concepción rosenzweiguiana del tiempo histórico, cuya singularidad se expresa aquí por medio del concepto «diferencia mesiánica». Siendo éste nuestro propósito, se procederá en él del modo siguiente. En un primer momento se abordará la temporalidad mesiánica tal como fue tematizada por Rosenzweig en La estrella de la redención, obra en la que cristaliza el nuevo pensamiento propuesto por el pensador judeoalemán. El marco para abordar esta noción de temporalidad será la querella sobre la secularización como categoría interpretativa de la Modernidad, cuya clave reside en la relación entre lo sagrado y lo profano. La concepción rosenzweiguiana de la temporalidad se vinculará así a la posibilidad de la «nueva secularización»1 (neue Säkularisation) presentada por Rosenzweig como alternativa, acaso no antagónica sino meramente agonal, a la cristianización del mundo que según el autor de La estrella comporta el concepto hegeliano de mundanización (Verweltlichung). El segundo de los apartados del presente texto estará consagrado por ello a la exposición de la interpretación de esta categoría, central en la filosofía de Hegel, que

\footnotetext{
${ }^{1}$ Cfr. Rosenzweig, F., Der Mensch und sein Werk. Gesammelte Schriften (I): Briefe und Tagebücher 2 (1918-1929) [GSI, 2], Martinus Nijhoff, Haag, 1979, p. 889.
} 
Rosenzweig presenta tanto en Hegel und der Staat como, siquiera implícitamente, en el epígrafe de La estrella que lleva por título «Política mesiánica»².

La verificación de la articulación hegeliana de filosofía política y filosofía de la historia en la Primera Guerra Mundial provocó en Rosenzweig su definitivo distanciamiento respecto de la política en la que, hasta 1917, había depositado aún ciertas esperanzas para Alemania y, por extensión, para Europa, así como respecto de toda concepción de la historia como sede de la reconciliación del mal. El nuevo pensamiento de Rosenzweig surge a partir de una lucha contra la teodicea hegeliana (e historicista) y, al mismo tiempo, por mor de una concepción de la temporalidad cuya novedad será determinada a continuación a partir de una muy sucinta confrontación con las propuestas igualmente antihistoricistas de Martin Heidegger y Emmanuel Levinas. En el tercer apartado del trabajo se mostrará en definitiva que, a diferencia del pensador de Meßkirch, tanto Rosenzweig como Levinas no se limitan a hacer del tiempo la cuestión fundamental de la ontología, sino que, para ambos pensadores judíos, «tomar en serio el tiempo» resulta necesariamente indisociable de la cuestión de la alteridad y, por tanto, de la ética -o, como gustaba en llamarla Rosenzweig a fin de distinguir su propuesta del deontologismo kantiano, de la metaética-. Desde este punto de vista, tomar en serio la diferencia ontológica es sinónimo de tomar en serio al otro del sí-mismo (Selbst), cuya distinción respecto de la mera personalidad (Persönlichkeit) constituye el núcleo último de la antropología de Rosenzweig. Del carácter decisivo tanto de la temporalidad como de la alteridad para la comprensión rosenzweiguiana de la existencia humana emerge, como núcleo mismo del nuevo pensamiento, una concepción diacrónica de la temporalidad, entendida ésta no como tiempo en el que tiene lugar una sucesión de acontecimientos, sino como tiempo que acaece él mismo a través de la temporalización de Dios, mundo y hombre en recíproca relación ${ }^{3}$. A modo de conclusión, se presentarán las diferentes posibilidades de temporalización que, según Rosenzweig, son propias del hombre, así como sus correspondientes relaciones con el temporalizarse de Dios y del mundo, esto es, sus diversos efectos de carácter teológico-político.

\footnotetext{
2 Cfr. Rosenzweig, F., La estrella de la redención [EdR], trad. de. M. García-Baró López, Sígueme, Salamanca, 1997, 389ss.

3 El sí-mismo rosenzweiguiano, por tanto, no será tomado aquí en consideración en tanto que elemento del antemundo, que en cuanto tal permanece al margen de toda relación con Dios y el mundo, sino desde un punto de vista ontológico ulterior, situándolo más allá de su dimensión puramente ideal, no efectiva y atemporal (cfr. EdR, 103-132). En efecto, desde el momento mismo en que entra en relación con los otros dos protofenómenos, adentrándose así en el plano de la temporalidad, el sí-mismo abandona eo ipso toda horizontalidad elemental, deja de ser mero elemento y deviene alma amada por Dios, es decir, un hombre llamado a la temporalización de la redención en la forma de su anticipación (cfr. EdR, 201-315).
} 


\section{1. «Temporalidad mesiánica» $\mathbf{y}$ «nueva secularización»}

Llamamos aquí «temporalidad mesiánica» a la concepción rosenzweiguiana del tiempo, en tanto en cuanto esta concepción del tiempo, como método de la «filosofía experienciante» (erfahrende Philosophie) de Rosenzweig, fundamenta su «teoría mesiánica del conocimiento» ${ }^{4}$. Obviamente, el adjetivo «mesiánico» posee una connotación religiosa, pero el pensamiento rosenzweiguiano no debe por ello ser considerado una filosofía de la religión, ni tampoco un ejemplo de teología judía. Tal y como el propio Rosenzweig se vio impelido a aclarar tras la publicación de $L a$ estrella, su nuevo pensamiento es un sistema de filosofía aconfesional cuyo núcleo en modo alguno puede ser identificado con una determinada religión, ni siquiera con el judaísmo ${ }^{5}$. Si el pensamiento rosenzweiguiano es mesiánico no lo es en el sentido de ningún mesianismo determinado ni, de hecho, en el de «Ismo» alguno 6 . La estrella no trata de ningún «mesianismo», sino de lo mesiánico o, por expresarlo con palabras de Jacques Derrida, de la «mesianicidad sin mesianismo»7 en que consiste la estructura mesiánica que, en el caso de Rosenzweig, se cifra en una determinada relación del hombre con Dios, a través de Dios con los otros hombres $\mathrm{y}$, por medio de éstos, con el mundo como un todo. En último término, esta relación estriba en la temporalización que acontece como «tiempo justo» (rechte Zeit), esto es, en la co-temporalización adecuada del hombre y las otras dos «facticidades» (Tatsächlichkeiten) o «protofenómenos» (Ürphanomene) a partir de las cuales Rosenzweig construye su sistema ${ }^{8}$.

Por medio de la distinción entre personalidad y sí-mismo, a la que atenderemos en mayor detalle más adelante, la antropología rosenzweiguiana muestra que todo hombre, en la medida en que es capaz de alcanzar la santidad, es capaz eo ipso de mantener una relación justa desde el punto de vista de la temporalidad tanto con el mundo como con los otros hombres, tomando para ello como punto de partida un

\footnotetext{
${ }^{4}$ Cfr. Rosenzweig, F., «El nuevo pensamiento. Observaciones adicionales a "La estrella de la redención” (1925)» [NP], en El nuevo pensamiento, trad. de I. Reguera, Visor, Madrid, 1989, pp. 51 y 74 ss.

5 Cfr. NP, 45. Sobre la aconfesionalidad de la propuesta filosófica de Rosenzweig, cfr. SchmiedKowarzik, W., «Differenzierung zum "Wir” bei Rosenzweig», en M. Brasser - H. M. Dober (eds.), Rosenzweigs Jahrbuch V. Wir und die Anderen, Karl Alber, Freiburg, 2010, pp. 44-48 y Reinhard, K., «Messianism and the Neighbor», en M. Brasser (ed.), Rosenzweig Jahrbuch I. Rosenzweig heute, Freiburg-München, Karl Alber, 2006, p. 119.

6 Cfr. EdR, 493, así como García-Baró, M., La compasión y la catástrofe. Ensayos de pensamiento judio, Sígueme, Salamanca, 2007, p. 243.

7 Cfr. Derrida, J., Espectros de Marx. El estado de la deuda, el trabajo de duelo y la nueva Internacional, trad. de J. M. Alarcón - C. de Peretti, Trotta, Madrid, 1995, p. 73, así como Dubbels, E., Figuren des Messianischen in Schriften deutsch-jüdischer Intellektueller 1900 - 1933, de Gruyter, Berlin, 2011, p. 35.

8 Cfr. EdR, 63-124, así como, sobre el tiempo justo, EdR, 327 ss.
} 
nexo privilegiado y de carácter heterónomo con Dios que, como señálabamos más arriba, permanece al margen de toda religión determinada9. De este modo, Rosenzweig hace referencia a la unidad de todos los hombres en su relación con la divinidad al margen de todo contenido teológico determinado (dogma) a partir de la irreducible distinción entre lo santo y lo sagrado o, en otros términos, operando una deconstrucción de lo sagrado a fin de sacar a relucir aquello que es propio de toda verdadera experiencia de carácter religioso: lo santo o, más exactamente, la santidad misma, que en cuanto tal no debe confundirse con forma alguna de sacralidad.

Lo sagrado es aquello no profano que toda religión absolutiza, o incluso lo profano mismo cuya absolutización o sacralización permite paradójicamente la neutralización moderna de lo sagrado, es decir, su secularización o profanación. Por su parte, lo santo escapa tanto al dogmatismo o fanatismo religioso como al securalista, a la manera de un umbral entre lo sagrado -o espiritual, acaso específicamente eclesiástico, como veremos- y lo profano -o mundano- que en cuanto tal no participa de esta perversa dicotomía cuya dialéctica determina la historia occidental, sino que, como resto suyo, más bien denuncia permanentemente la totalización a la que conduce. La propuesta de Rosenzweig apunta en definitiva a la superación de la dialéctica de lo sagrado y lo profano que determina la concepción de la Modernidad como resultado de un proceso de secularización y de este modo ofrece la posibilidad de pensar una nueva secularización cuya novedad consiste en evitar los peligros de la tiranía, o al menos en denunciarlos, mediante el combate contra la sacralización de lo profano y la propuesta de una nueva orientación para la política a través del amor al prójimo10. Rosenzweig encuentra la posibilidad de una reorientación tal de la política en un modo de la correlación Dios-hombre que es capaz de producir efectos redentores en el mundo, es decir, en una concepción decididamente anti-marcionita de la revelación como respuesta a la blasfema e idólatra mundanización de Dios operada por el Estado y, en particular, por el Estado hegeliano, conforme éste es interpretado por Rosenzweig.

\section{El desengaño hegeliano de Rosenzweig y el surgimiento del nuevo pensamiento}

En efecto, el origen de la concepción rosenzweiguiana de la secularización se encuentra en el estudio del origen y el devenir de la idea hegeliana de Estado pre-

\footnotetext{
9 Sobre la distinción rosenzweiguiana entre el hombre entendido como personalidad, es decir, como un hombre entre otros hombres -a la manera del Uno (Man) heideggeriano- y el hombre como símismo metaético, cfr. EdR, 103 ss., así como infra.

10 Cfr. Rosenzweig, F., «“Célula originaria” de La estrella de la redención», en El nuevo pensamiento, op. cit., p. 20, así como Casper, B., Das dialogische Denken. Franz Rosenzweig, Ferdinand Ebner und Martin Buber, Karl Alber, Freiburg i. Br., $2002^{2}$ (19671), pp. 69-71.
} 
sentado por el pensador judeoalemán en su Hegel und der Staat y, en particular, en su hermenéutica de aquellos pasajes de la Enciclopedia (\$552) y de la Filosofia del Derecho (\$270) en los que Hegel tematiza la relación entre religión (cristianismo) y Estado desde el punto de vista de la historia universal. Como es de sobra conocido, Hegel acepta en estos textos la idea de una neutralidad religiosa del Estado moderno y, por lo tanto, la idea de tolerancia fundada en la separación institucional de Iglesia y Estado que resultó de la Reforma. Sin embargo, en el marco del sistema filosófico de Hegel las relaciones del Estado con la religión no se agotan en el plano del derecho positivo, es decir, en la igualdad de todas las religiones ante la ley. Para Hegel no es suficiente con dar al César lo que es del César y a Dios lo que es de Dios, sino que debe determinarse conceptualmente, en el plano especulativo, aquello que corresponde a la religión y al Estado como figuras del Espíritu. Desde este punto de vista no hay en Hegel una separación entre lo religioso y lo político, sino que, al contrario, la religión aparece como basamento del Estado ${ }^{11}$. El derecho del Estado racional no radica pues en sí mismo, sino en el contenido de la religión y, de hecho, en el contenido de una religión: el luteranismo. El Estado es la realización objetiva de la misma verdad que la religión luterana alcanza sólo subjetivamente y, en este sentido, es la realización histórica del Espíritu en el mundo o el resultado de su mundanización (Verweltlichung). Existe por tanto una unidad esencial entre religión (luterana) y Estado (ético o racional). En tanto que realización de la eticidad, el Estado es realización de la religión en la que esta eticidad-como por lo tanto también el propio Estado- encuentra su sustancialidad y su base ${ }^{12}$.

«Mundanización» se refiere en Hegel a la realización del cristianismo a través de una espiritualización de lo profano, entendida como una transformación del mundo por los principios espirituales del cristianismo y de éstos, a su vez, por el mundo. El movimiento dialéctico del que la Modernidad es resultado consistiría así en una mundanización de lo sagrado y una sacralización de lo temporal en la que el Estado aparece como instancia de mediación ${ }^{13}$. Sin ser geistlich (eclesiástico), es geistig (espiritual), de tal manera que la Iglesia no posee el monopolio de lo espiritual y el Estado -al menos el Estado racional o ético- no es simplemente una institución secular, sino la realización del Espíritu en el mundo. La importancia de las relaciones entre Iglesia y Estado en este contexto es señalada por Rosenzweig desde el primer momento: «La Iglesia, el Imperio, el Estado y el Pueblo» es, en conexión con el celebérrimo dístico hegeliano sobre la racionalidad de lo realmente efectivo

\footnotetext{
11 Cfr. Hegel, G. W. F., Principios de la Filosofía del Derecho o Derecho Natural y Ciencia Política, tr. J. L. Vermal, Edhasa, Barcelona, 1988, § 270, pp. 335ss.

12 Cfr. Hegel, G. W. F., Enciclopedia de las ciencias filosóficas en compendio, tr. R. Valls Plana, Alianza, Madrid, 1997, §552, pp. 572ss.

13 Cfr. Rivera García, A., «La secularización después de Blumenberg», Res Publica, 11-12, 2003, pp. 97-98.
} 
y viceversa, el tema con el que el Hegel es inaugurado por su autor. La cuestión, empero, sale a relucir de modo eminente en el apartado dedicado por Rosenzweig a la época de Hegel en Jena, en la que la doctrina hegeliana del Estado adquiere carácter sistemático y se integra, por tanto, en una filosofía de la historia universal. El Estado compite entonces con la Iglesia por la condición de destino y el enfrentamiento entre ambas instituciones pasa a responder a una necesidad histórica interna propia de la Edad Moderna. Tras la unidad de ambas en Grecia y el sometimiento del Estado a la Iglesia durante el Medioevo, el principio del Estado moderno consiste en su independencia respecto de la Iglesia, o sea, en su secularización. Ahora bien, como se ha sugerido más arriba, Hegel no emplea este término jurídico, pues estuvo dotado de una fuerte connotación anticristiana y, de hecho, en buena medida antigermánica ${ }^{14}$.

En correspondencia con la distinción entre lo espiritual y lo eclesiástico, «mundo» no se identifica en Hegel con el saeculum católico-medieval, ni obviamente tampoco con la naturaleza de la bella mitología del paganismo que el catolicismo había desdivinizado. Es más bien el mundo de la religión del futuro hacia la que conduce la última figura histórica del cristianismo, encarnada en el protestantismo. La doctrina de Lutero consuma en definitiva el destino histórico de la religión cristiana: la reconciliación de Estado y Reino de los Cielos en el plano del pensamiento, sólo a nivel de la conciencia, que sin embargo hace posible -señala Rosenzweig interpretando a Hegel- el Estado racional. Y, a la inversa, sólo hay cristianismo consumado en la medida en que produzca efectos sobre un Estado ético. Los dos destinos coincidirían así en uno de mayor altura, lo cual sin embargo no debe entenderse en el sentido de la unidad de Estado e Iglesia que añoraron los románticos y la Restauración. La lucha contra la secularización no se libra en el caso de Hegel por medio de una eclesialización del Estado, ni a través de una estatalización de la Iglesia, sino mediante una mundanización del Espíritu que es al mismo tiempo su más plena realización. Su condición de posibilidad, como acabamos de indicar, vino dada por la separación institucional de Iglesia y Estado que propició la separación interna de la Iglesia. Sólo tras la Reforma fue posible que el Estado alcanzara la eticidad y la racionalidad autoconscientes, su determinación más plena o su destino. Catolicismo y Estado racional o ético son en Hegel resueltamente incompatibles.

Conforme a la interpretación de Rosenzweig, la reconciliación de la realidad con el Espíritu, y del Estado con la conciencia religiosa, se produce en Hegel como resultado de una absolutización (histórica) del protestantismo y del Estado (prusiano). El autor de La estrella añade que no hay mayor testimonio de esto que el par-

14 Entre 1555 (firma de la Paz de las Religiones) y 1803 (fecha en la que el Imperio secularizó sus principados eclesiásticos, salvo tres de ellos, para terminar disolviéndose en 1806) «secularización» y «destrucción del Sacro Imperio Romano Germánico» fueron prácticamente sinónimos. 
ticular discurso de rectorado de Hegel, pronunciado por el filósofo suabo con ocasión de la celebración del tercer centenario de la Confessio Augustana, cuya presentación en la Dieta de Augsburgo celebrada en 1530 significó según Rosenzweig el comienzo de la época cuyo final, visto retrospectivamente, no tuvo su inicio en tiempos de Hegel, sino en la década de esplendor de Otto von Bismarck. Ahora bien, para entonces el filósofo de Stuttgart pudo aparecer para la teoría del Estado alemán «como un filósofo de la historia, a lo sumo, pero no como un filósofo del Estado»15. Si Hegel no había podido seguir el desarrollo nacional alemán, éste, a través fundamentalmente de Heinrich von Treitschke, había recurrido a la historia universal hegeliana para justificar el sacrosanto egoísmo estatal y la estrechez tanto interior como exterior de la obra del Canciller de Hierro ${ }^{16}$.

En 1920, momento en que Rosenzweig establecía el anterior diagnóstico con vistas a la publicación de su Hegel, un campo de ruinas ocupaba el lugar en el que otrora se erigía el Reich ${ }^{17}$. No obstante, ya inmediatamente después del final de la Primera Guerra Mundial, en diciembre de 1919, Rosenweig afirmaba haberse desentendido de la cuestión del Estado18. El desengaño político de Rosenzweig no hunde sus raíces en la derrota militar de Alemania, sino en la dimisión del Canciller Theodor von Bethmann (1917) y la simultánea capitulación de la idea centroeuropeísta en cuya realización el filósofo de Kassel había depositado sus esperanzas respecto al desenlace de la guerra ${ }^{19}$. Rosenzweig vio en el surgimiento y el fortalecimiento de «la conciencia metapolítica nacional» 20 de los pueblos centroeuropeos

15 Rosenzweig, F., Hegel und der Staat [HuS], Surhkamp, Frankfurt a. M., 2013, 2010, pp. 529. Subrayado mío.

16 Pero «estatal» no significa necesariamente «nacional», es decir «estatal-nacional». Lo que separa a Hegel del final del XIX es lo que separa a su Estado respecto de la idea de Estado-nacional. Ésta fue introducida en Alemania, señala Rosenzweig, únicamente post-Hegel-mortuum. De modo muy conciso, cabría resumir las conclusiones del Hegel de Rosenzweig con las siguientes palabras: lo que la nación fue para el Estado pensado por Treitschke y realizado por Bismarck, eso mismo fue la voluntad del individuo para el Estado ideado por el liberal-estatal que había sido Hegel -convertido no obstante por Hermann Heller, más tarde, dice Rosenzweig, en un liberal-nacional de la época de Bismarck-. Cfr. Rosenzweig, F., «Algunos libros sobre Hegel», en El país de los dos ríos. El judaísmo más allá del tiempo y la historia, trad. de I. Ortega, Encuentro, Madrid, 2014, p. 341. De esta cuestión se ocupó José Luis Villacañas en su conferencia «Hegel y el Estado. Apuntes sobre la crisis de Weimar», pronunciada el 30 de enero de 2014 en la Facultad de Filosofía de la Universidad Complutense de Madrid. Respecto del «momento hegeliano», debe consultarse Duque, F., La Restauración. La escuela hegeliana y sus adversarios, Akal, Madrid, 1999, así como, respecto de Treitschke, HuS 528 ss.

$17 \mathrm{HuS}, 18$.

18 Cfr. GSI, 2, 656.

19 Cfr. Herzfeld, W. D., Rosenzweig, «Mitteleuropa» und der Erste Weltkrieg. Rosenzweigs politische Ideen im zeitgeschichtlichen Kontext, Karl Alber, Freiburg-München, 2013.

20 Rosenzweig, F., «Der Jude im Staat», en Der Mensch und sein Werk. Gesammelte Schriften (III): Zweistromland. Kleinere Schriften zu Glauben und Denken, Martinus Nijhoff, Haag, 1984 [GSIII], p. 554. 
la única posibilidad de salvación para Alemania, es decir, la única posibilidad de evitar una segunda guerra mundial como la que el propio Rosenzweig había vislumbrado en las páginas finales de la primera parte de su premonitorio Globus ${ }^{21}$. La «política ideal bethmanniana» ${ }^{22}$ se vio sin embargo derrotada por el realismo político de cuño bismarckiano, adaptado ahora a las pretensiones imperialistas de las que no obstante siempre renegó Bismarck, incluso hasta el punto de abandonar su cargo. La victoria definitiva de esta Realpolitik en la Alemania inmediatamente anterior a la desaparición del II Reich se consumó en el momento en el que los generales Erich Ludendorff y Paul von Hindenburg forzaron la dimisión de Bethmann, sustituyéndolo por Georg Michaelis. Más tarde, los dos cargos militares participaron de un modo u otro en el ascenso político de la tiranía nacionalsocialista: Ludendorff apoyó a Adolf Hitler en el fallido Putsch de 1923 y Hindenburg, Presidente de la República de Weimar entre 1925 y 1933, otorgó finalmente la Cancillería al líder del NSDAP. La historia posterior a la muerte de Rosenzweig terminó así por dar la razón al pensador judeoalemán 23 .

El fracaso de la idea de Centroeuropa defendida por Rosenzweig durante la guerra supuso su alejamiento definitivo respecto del historicismo y el hegelianismo cuya verificación había significado la catástrofe bélica, según la interpreta el autor de La estrella. La re-evaluación rosenzweiguiana de la historia y de la política es efecto de un desengaño hegeliano 24 . La propuesta metahistórica y metapolítica que contiene el opus magnum de Rosenzweig se refiere a la resistencia contra el horror de la historia política occidental y el campo de ruinas que ésta deja tras de sí. En definitiva, podemos decir que la advertencia contra la tiranía con la que el autor de La estrella abre la tercera parte de su obra capital había sido desoída en 1914 y, como hoy sabemos, volvió a serlo más tarde25. Quizá por ello deba hoy ser tenida

21 Cfr. Rosenzweig, F., «Globus. Estudios sobre la doctrina histórico-universal del espacio», en Escritos sobre la guerra, ed. de R. Navarrete, Sígueme, Salamanca, 2015, pp. 115-204.

22 Cfr. Rosenzweig, F., Der Mensch und sein Werk. Gesammelte Schriften (I): Briefe und Tagebucher 1 (1900-1918) [GSI, 1], Martinus Nijhoff, Haag, 1979, p. 322.

23 Esto supo verlo ya Levinas en su vindicación de la vigencia del pensamiento rosenzweiguiano tras la Shoá. Cfr. Levinas, E., «Franz Rosenzweig: un pensamiento judío moderno», en Fuera del sujeto, trad. de R. Ranz Torrejón - C. Jarillot Rodal, Caparrós, Madrid, 1997, p. 16. El original francés data de 1987.

24 Cfr. Avineri, S., «Rosenzweig's Hegel Interpretation: Its Relationship to the Development of His Jewish Reawakening», en Schmied-Kowarzik, W. (Hrsg.), Der Philosoph Franz Rosenzweig (18861929): Internationaler Kongreß-Kassel 1986, II, Karl Alber, Freiburg-München, 1988, pp. 831-838.

25 Cfr. EdR, 319 ss. In tyrannos! es, en efecto, el Motto que preside la Introducción del tercer libro de La estrella. Por lo demás, es más que digno de ser reseñado en este contexto, es decir, teniendo en cuenta la ingente labor de archivo llevada a cabo por Rosenzweig para la elaboración de su tesis doctoral sobre la idea hegeliana de Estado, el hecho de que esta expresión latina apareciese en el álbum de Hegel, muy probablemente para referirse -laudatoriamente- al regicidio de Luis XVI. Cfr. Rocco, V., La vieja Roma en el joven Hegel, Maia, Madrid, 2011, p. 59, así como D’Hondt, J., Hegel, trad. de C. Pujol, Tusquets, Barcelona, 2002, p. 72 y HuS, 40-41. 
si cabe más en cuenta a fin de evitar una nueva catástrofe, con objeto por tanto de reorientar el transcurso de la historia, ya que no es otra cosa lo que reprocha Rosenzweig a la tiranía sino una temporalización constitutivamente inoportuna, que se da siempre a destiempo con respecto a la temporalización del otro. El tirano no toma suficientemente en serio el tiempo del otro -Dios, el mundo y los otros hombres-, totaliza o absolutiza su propio tiempo y traiciona el carácter relacional o diacrónico de la temporalidad propiamente dicha. Ésta, por lo demás, no debe ser entendida, en palabras de Rosenzweig, como un «tiempo en el que algo acaece», es decir, como estructura trascendental, ontológica y -precisamente- atemporal, sino como «tiempo que acontece por sí mismo» 26.

Este carácter relacional del tiempo que acaece por sí mismo no se refiere sólo al acaecer de este tiempo en el tiempo cronológico, sino que la temporalidad mesiánica rosenzweiguiana es relacional en cuanto tal, en el sentido de que no es sino una co-temporalización de diversas temporalizaciones. Remite a una concepción diacrónica de la temporalidad conforme a la cual la temporalización de un proto-fenómeno se da a través del acaecimiento de su relación con la temporalización de los otros elementos. Rosenzweig resume este punto con las siguientes palabras: «Necesitar tiempo significa no poder anticipar nada [ni como personalidad o individuum ni como sí-mismo cerrado en sí mismo, es decir, como místico, R. N.], tener que esperarlo todo, depender de otros en lo propio» 27 . La posibilidad de una anticipación de la redención depende de la co-temporalización de los tres proto-fenómenos, o sea, del acaecer de los tres elementos en recíproca relación. Si la novedad del pensamiento de Rosenzweig se cifra justamente en «tomar en serio el tiempo», esto no significa otra cosa, como el propio autor de La estrella explica, que un «necesitar al otro» 28 . Por último, en cuanto acaeciente, este tiempo debe ser entendido como un tiempo que no representa final (Ende) alguno de la historia, como tampoco una meta (Ziel) ideal o atemporal del continuum temporal de la historia, sino la anticipación del final de los tiempos: la temporalización presente del futuro final de la historia que, como tal, no puede identificarse con el final mismo, pero tampoco con ningún intento de consumar (voll-enden ${ }^{29}$ ) o finiquitar (fertig zu machen) el mundo. Éste permanece en un estado constante de inacabamiento (Unfertigkeit) y,

\footnotetext{
${ }^{26}$ NP, 58. Cfr. asimismo Garrido Maturano, Á. E., «“El tiempo que acontece por sí mismo”. La estructura de la temporalidad en la Estrella de la Redención de Franz Rosenzweig", en Themata. Revista de Filosofia de la Universidad de Sevilla, 32, 2004, pp. 99-118.

$27 \mathrm{NP}, 63$.

$28 \mathrm{NP}, 63$.

29 Voll-enden en el sentido de la teoría hegeliana de la secularización, o de cierta interpretación suya más bien, como identificación dialéctica de lo efectivo (mundano) y lo racional (espiritual) que, por medio de la reconciliación del mal que presupone una concepción de la historia como teodicea, conduce a las catastróficas consecuencias de una divinización de la historia y del Estado como portador suyo.
} 
por tanto, no es sino un mundo que deviene (eine werdende Welt) en pos de su esencialización (Verwesentlichung) ${ }^{30}$.

De acuerdo con Rosenzweig, la piedra de toque de la incompletitud constitutiva de la política consiste precisamente en que el mundo no está acabado, sino que es un mundo en devenir, un mundo inacabado que sin embargo posee la determinación de su futuro acabamiento (o redención). Por esta razón, como mera eternización humana del mundo, la política fracasa de continuo. El aspecto decisivo del pensamiento teológico-político de la temporalidad en Rosenzweig consiste en que la palabra «mundo» significa de una parte el mundo concreto, pero de otra representa una horizonte profético de esperanza que en cuanto tal no es una meta que deba ser esperada de manera indefinida, sino un final que viene eternamente, que acontece en el presente como futuro anticipado ${ }^{31}$.

\section{La novedad del nuevo pensamiento rosenzweiguiano}

Rosenzweig no niega la articulación hegeliana de historia y política, sino su carácter totalizante, es decir, el cerrarse en sí mismo del mundo y la consiguiente divinización o sacralización de la inmanencia, o de lo profano, que paradójicamente implica. Rosenzweig no combate la historia, sino la historia concebida como teodicea32. Más que como justificación del mal, «historia» significa para él «catástrofe», esto es, «que se cumple el reino del bien pero también el del mal; ;las dos civitates"! El mundo, pues, se va haciendo, cada vez más, tanto mejor como peor» ${ }^{33}$. Así entiende Rosenzweig el acontecimiento histórico-universal decisivo que representó para él la Primera Guerra Mundial en tanto que decisión (Ent-scheidung) y, al mismo tiempo, corte (Scheidung), Krisis: realización histórica de la «filosofía pensante» (denkende Philosophie) que Rosenzeweig identifica con el conjunto de la tradición filosófica occidental «desde Jonia hasta Jena» ${ }^{34}$. Como en el caso de Heidegger, quien a diferencia de Rosenzweig vio en Nietzsche, y no en Hegel, la consumación de la metafísica, este final de la filosofía no significa para el autor de La estrella el final del pensar, sino que, al contrario, en este punto de la historia de la filosofía emerge la posibilidad de un nuevo comienzo y de un nuevo pensamiento. En el caso de Rosenzweig la novedad consiste en el hecho de que el pensamiento

\footnotetext{
30 Cfr. EdR, 266 ss.

31 Cfr. Casper, B., «Der Andere, der Dritte und die Bürgschaft für die Gerechtigkeit», Archivio di Filosofia LXXIV, 1-3 (2006) 190.

32 Cfr. GSI, 1, 112-113, así como Hegel, G. W. F., Lecciones sobre la filosofía de la historia universal, trad. de J. Gaos, Alianza, Madrid, 1980, p. 56.

33 Rosenzweig, F., «Paralipomena», en El país de los dos ríos, op. cit., p. 247.

34 EdR, 52.
} 
filosófico se desprende de todo afán en relación al conocimiento del todo atemporal y se propone hacer la experiencia del tiempo en tanto que acaecer diacrónico (y dialógico), ya no pensarlo como estructura trascendental y a priori 35 .

Rosenzweig y Heidegger, como más tarde también Emmanuel Levinas, coinciden al señalar la temporalidad como horizonte de aquello verdaderamente digno de ser pensado ${ }^{36}$. Tal es el parentesco existente entre estos tres autores. La gran diferencia entre los dos filósofos judíos, por un lado, y el autor de Ser y tiempo, por otro, se encuentra en el papel desempeñado por la alteridad a la hora de tomar en consideración el tiempo. Tanto Rosenzweig como, influido por éste, Levinas, enfatizan el carácter diacrónico de la temporalidad, mientras que el pensamiento de Heidegger permanece bien en la pregunta por la temporalidad de un existente aislado (primer Heidegger), bien en la pregunta por la temporalidad del ser en relación a un existente aislado (segundo Heidegger) ${ }^{37}$. Rosenzweig y Levinas toman la co-temporalización del tiempo más en serio que Heidegger, en tanto en cuanto ambos pensadores consideran seriamente al otro del sí-mismo como otro sí-mismo: como otro existente o, en el caso de Levinas, incluso como lo completamente otro, situado más allá de todo sí-mismo y de todo existente. En otras palabras: en tanto en cuanto el existir-con del ser-en-el-mundo que en cuanto tal es el existente, es

\footnotetext{
35 En el caso del autor de Ser y tiempo, cfr. Heidegger, M., «El final de la filosofía y la tarea del pensar», en Tiempo y ser, trad. de J. L. Molinuevo, Tecnos, Madrid, 1999, pp. 77-93. Sobre la posibilidad de conocer el Todo, véase la introducción de Rosenzweig al primer volumen de La estrella (EdR, 43 ss.), dirigido explícitamente por Rosenzweig in philosophos, es decir, en contra del «viejo pensamiento».

36 Sobre el parentesco y, al mismo tiempo, las diferencias existentes entre Husserl, Heidegger, Levinas y Rosenzweig, cfr. Casper, B., « $\square$ Autrement que Husserl' et $\square$ au-delà de’ Heidegger. Zur Bedeutung von Emmanuel Levinas für eine künftige Geschichte des Denkens», en I. Kajon - E. Baccarini - F. Brenzi (Eds.), Emmanuel Levinas. Prophetic Inspiration and Philosophy. Atti del Convegno internazionale per il Centenario della nascita, Giuntina, Firenze, 2008, pp. 399-414; Id., «Zeit und messianische Zeit. Zu einem Grundphänomen des religiösen Geschehens», en R. Kaufmann (ed.) Scientia et Religio. Religionsphilosophische Orientierungen, Thelem, Dresden, 2005, pp. 97-110; Id., «Zeit und Heil. Überlegungen zu Martin Heidegger und einigen gegenwärtigen jüdischen Denkern», en M. M. Olivetti (ed.), Ebraismo Ellenismo Christianismo II, Cedam, Padova, 1985, pp. 173-195; e Id., «Ereignis (acaecimiento) en la concepción de Franz Rosenzweig y en el pensamiento de Martin Heidegger», trad. de Á. E. Garrido Maturano, en Escritos de Filosofía, 29-30, 1996, pp. 3-20. Sobre la relación entre Heidegger y Rosenzweig pueden consultarse asimismo las respectivas interpretaciones de K. Löwith y P. E. Gordon, si bien ambas divergen, por razones distinas, de la posición aquí defendida. Cfr. Löwith, K., "Martin Heidegger y Franz Rosenzweig. Un agregado a El ser y el tiempo (1942/1943)", en Heidegger, pensador de un tiempo indigente. Sobre la posición de la filosofia en el siglo XX, trad. de R. Setton, FCE, Buenos Aires, 2006, pp. 91-126, así como Gordon, P. E., Rosenzweig and Heidegger. Between Judaism and German Philosophy, University of California Press, BerkeleyLos Angeles, 2003.

37 Cfr. Casper, B., «Zeit und Heil. Überlegungen zu Martin Heidegger und einigen gegenwärtigen jüdischen Denkern», loc. cit., pp. 187 ss.
} 
pensado por Rosenzweig y Levinas con mayor profundidad, a partir de una perspectiva (meta)ética.

La ontología en la que permanece el pensamiento fenomenológico-hermenéutico de Heidegger es remitida tanto por Rosenzweig como por Levinas a la (meta)ética, que de hecho en el caso del discípulo tanto de Husserl como de Heidegger deviene prima philosophia. Pero también Rosenzweig concibe lo metaético como verdadera clave de bóveda de su pensamiento. La dignididad del símismo como materia para el pensamiento no es sólo evidente por sí misma, es decir, irreductible tanto a la de Dios como a la del mundo, sino lo verdaderamente decisivo, de tal manera que la pregunta por el sí-mismo, siempre y cuando sea tomada en serio, distingue nuevo pensamiento y vieja filosofía ${ }^{38}$. Si el ser, en tanto que tiempo, es simultáneamente humano, mundano y divino, y si el acaecer del tiempo sólo puede darse a partir del presupuesto de la separación de estos protofenómenos, en tanto en cuanto no es otra cosa que su recíproca relación, la temporalización del hombre metaético es la piedra de toque del sistema filosófico rosenzweiguiano.

En el libro de La estrella dedicado a la meta-ética Rosenzweig identifica la personalidad con el animal político aristotélico ${ }^{39}$. Desde esta perspectiva irrenunciable, el Estado es bueno, o cuando menos necesario, en razón de la maldad humana, es decir, del natural ser-en-el-mundo del hombre como individualidad enfrentada a otras individualidades. Es también necesario en razón del ser-en-el-mundo ético, político e histórico del hombre, que determina el surgimiento del Estado como siempre necesariamente enfrentado a otros Estados en razón de su propio derecho a la existencia, cuando no de su pretendido derecho al mundo. El Estado debe existir a fin de poner freno a la natural e ilimitada libertad para la voluntad propia del hombre que se dirige al mundo pasando por alto el resto de hombres ${ }^{40}$. Rosenzweig, por tanto, no niega el valor del Estado, si bien se resiste a aceptar que lo propio del seren-el-mundo del hombre esté restringido a su ser-en-el-mundo-a-la-mano. Frente a esta posibilidad inmediata la libertad de cada hombre singular puede dirigirse a su propio contenido, a la peculiaridad del carácter propio. Este hundirse en sí mismo del hombre en cuanto sí-mismo y ya no mero individuo permite que, sin negar el mundo pero retraído del mundo, sea capaz de no tratarlo como mera existencia fenoménica ligada al instante. El sí-mismo está en relación con la creación, ya no a

38 GSI, 2, 606: «La concepción originaria descansa en el concepto de lo metaético». Cfr. Casper, B., «Zeit und Heil. Überlegungen zu Martin Heidegger und einigen gegenwärtigen jüdischen Denkern», loc. cit., p. 183.

39 Cfr. EdR, 112. Sobre la distinción entre personalidad y sí-mismo, es decir, entre zoon politikon y homo revelationis en Rosenzweig, cfr. Kohr, J., "Gott selbst muss das letzte Wort sprechen...». Religion und Politik im Denken Franz Rosenzweigs, Karl Alber, Freiburg-München, 2008, pp. 267 ss. 40 Cfr. GSI, 2, 656-657. Sobre esta cuestión, me permito remitir a mi artículo «,Zwänge er durch die Kraft der Liebe, so wäre er das Höchste". Staatskritik und Liebesgebot im Denken Franz Rosenzweigs», en Proceedings of the Internationale Rosenzweig Gesellschaft 1, 2014, pp. 81-95. 
través del Estado, sino de un vínculo con lo más alto, aquello que no es ni hombre ni mundo.

La apertura a la revelación del Dios metafísico permite al sí-mismo escuchar el mandamiento divino del amor, es decir, no obedecer más en razón de la fuerza de una ley que es constitutivamente violenta, sino a través de la fuerza de un amor que no es ya amor propio (orgullosa altanería), mas amor por los otros (humildad no menos orgullosa $)^{41}$. La antropología rosenzweiguiana se adentra así en profundidades inaccesibles a un pensamiento puramente politológico: junto a la peligrosidad del hombre que habita el mundo como zoon politikon, Rosenzweig toma en consideración al hombre como signo de santidad, como señal de un mundo que permanece al margen de toda diferenciación mundana entre lo bueno y lo malo. Este mundo meta-ético es el propio del sí-mismo abierto a la revelación; un mundo que, sin identificarse con el mundo a la mano, se temporaliza en él prolépticamente, como figura suya. Este acontecimiento, y no por tanto la suspensión del ordenamiento jurídico que otorga normatividad al orden del mundo, constituye para Rosenzweig el milagro: la excepción o, más exactamente, lo excepcional que, como milagro propiamente dicho y no como mero efecto de la magia, no puede ser consumado por el hombre pero debe ser anticipado por él ${ }^{42}$.

El sí-mismo que alcanza la santidad no puede conformarse con el quietismo, no es un místico que niegue el mundo y renuncie al mundo ${ }^{43}$. Al contrario, puesto que Dios no es de este mundo y no puede ser propiamente mundanizado, el sí-mismo debe ocupar su puesto y producir efectos en el mundo tal y como Dios mismo lo haría. Esto significa amar el mundo a través del amor a otro sí-mismo, devenir amante del mundo a través del amor al prójimo que, como representante del mundo, puede ser cualquiera. No lo es de hecho en primer lugar el amigo en sentido político, sino, al contrario, el enemigo 44 . Por medio de esta acción del sí-mismo en el mundo se produce una ampliación del Yo al Nosotros: una anticipación, hic et nunc, de la comunidad mesiánica de la humanidad. La metaética rosenzweiguiana deviene así una metapolítica o, toda vez que está fundada en la relación del sí-mismo con Dios, una teología metapolítica que no niega simplemente la política mesiánica pero le procura una reorientación a través de aquello que escapa al concepto de lo político: el amor. Sólo éste hace justicia a lo propio del hombre, toda vez que no se limita a considerarlo un mero sujeto de derecho, es decir, un mero súbdito del Estado y, por ende, del poder.

\footnotetext{
41 Cfr. EdR, 212 ss.

42 Cfr. EdR, 136-138. Por «magia» se entiende aquí una interrupción humana del orden del mundo bien con vistas a su conservación, bien a su igualmente violenta reconfiguración: decisión soberana, en definitiva.

43 Cfr. EdR, 255ss.

44 Cfr. EdR, 266ss.
} 


\section{Lo metapolítico y su temporalización}

En La estrella de la redención, Rosenzweig se refiere a una concepción relacional del tiempo sin no obstante negar la temporalidad cotidiana, es decir, el tiempo de la personalidad y de aquellas realidades en las que, empezando por el Estado, la personalidad se desenvuelve naturalmente. Este tiempo que acaece por sí mismo sí niega, en cambio, el carácter absoluto del continuum de la historia, del mismo modo que la comunidad mesiánica de la humanidad anticipada por el amor al prójimo pone en cuestión lo político como única determinación del hombre sin negar por ello la existencia del enemigo. El tiempo que acaece por sí mismo se eleva por encima y a partir de la historia, poniendo así de manifiesto los límítes de los histórico, su carácter meramente pasajero y profano. Esto no significa que la contraposición existente entre la temporalidad mesiánica y el tiempo cronológico deba ser entendida en sentido excluyente, como si de dos temporalidades antagónicas se tratase. La relación entre ellas es, antes bien, agonal. El tiempo mesiánico se da en el tiempo cronológico homogéneo y vacío como contra-tiempo suyo, es decir, interrumpiendo el continuum, pero no consumándolo 45 . La temporalidad mesiánica no se refiere a ningún final de los tiempos, sino a la temporalización del futuro final como signo acaeciente, por anticipado, del futuro todavía no acontecido 46 .

«Acaeciente» y no «todavía no acontecido». La diferencia de significado existente entre estas dos expresiones referidas al futuro es la misma que cabe encontrar entre las concepciones mesiánica y cronológica del tiempo. Respecto del futuro, «acaeciente» y «todavía no acontecido» significan respectivamente «eterno» -en el

45 Sobre el carácter de contra-tiempo propio de la temporalidad mesiánica, cfr. Bensussan, G., Le Temps messianique. Temps historique et temps vécu, J. Vrin, Paris, 2001, pp. 124-126, así como Lanceros, P., «Contratiempo. De un borrón de tinta en el papel secante», en J. Barja-C. Rendueles (eds.), Mundo escrito. 13 derivas desde Walter Benjamin, CBA, Madrid, 2013, pp. 165-200.

46 No se está afirmando aquí por tanto, como por lo demás tampoco haría Rosenzweig, la existencia de una relación de oposición entre mesianismo y escatología, pues en efecto no tendría sentido alguno hacerlo. No ocurre que lo escatológico represente una traición a la concepción mesiánica de la temporalidad, ya que ésta se refiere a la temporalización o acaecimiento anticipado, precisamente, del final de los tiempos o eschaton, sin no obstante identificarse con él. Tal y como se nos señaló en una de las evaluaciones del presente trabajo, a cuyo autor se agradece aquí la invitación a precisar este aspecto, «lo mesiánico invita a lo escatológico y lo escatológico emerge de lo mesiánico», pero esta afirmación no significa que se identifiquen sin resto ni por lo tanto pone en entredicho la validez de la fórmula «diferencia mesiánica». Cuando se habla aquí de la diferencia entre lo escatológico y lo mesiánico no se niega la relación de esto último con la plenitud de los tiempos, o con la sobrevenida de la eternidad, sino el carácter definitivo de ésta cuando del acontecer del tiempo mesiánico se trata. Según nuestra interpretación, dicho carácter definitivo corresponde exclusivamente a la irrupción del eschaton, que en cuanto final de los tiempos está desprovisto de todo carácter temporal, a diferencia de lo que ocurre en el caso del tiempo mesiánico. Si el concepto de diferencia mesiánica establece una oposición es en todo caso entre lo mesiánico y las falsas o pretendidas escatologías políticas, es decir, entre lo mesiánico y aquello a lo que Rosenzweig se refiere con la expresión «política mesiánica». 
sentido de que adviene ya hoy y, en realidad, desde siempre-e «infinito» -en el sentido de lo que, como meta ideal de una serie infinita, es y permanece siempre inalcanzable en la propia serie-47. Si el amor pone en jaque el carácter absoluto de lo político, el tiempo que acaece diacrónicamente, es decir, como relación del homo amans con su prójimo, concede precisamente tiempo para emitir un juicio sobre la historia que Hegel había elevado a la condición de tribunal de la humanidad. Sin este juicio la propia humanidad permanece indefensa, hundida por completo en la inmanencia e incapaz de resisitir a la catástrofe continuada en que consiste la historia.

Una concepción mesiánica del tiempo histórico como la que cabe encontrar en Rosenzweig lleva implícita una crítica a la temporalidad que está a la base de la contrarrevolución. Al mismo tiempo, deconstruye la diferencia entre las violencias conservadora y fundadora de derecho, enfrentándose por tanto a la temporalidad revolucionaria y, por último, a la propia de una concepción de la historia como progreso48. Rosenzweig reduce a un único motivo estos tres modos en los que habitualmente se piensa el tiempo histórico, en la medida en que ve en todos ellos formas de retener el acontecimiento de la redención e incluso su anticipación, en el sentido del darse aquí y ahora la justicia que permanece al margen o en los márgenes del ordenamiento jurídico. Desde un punto de vista filosófico-histórico, al par «política-metapolítica» corresponde entonces el par «retención-anticipación». En ambos casos la relación entre los términos no puede ser entendida de modo excluyente, sino nuevamente en un sentido agonal, puesto que la anticipación (el tiempo mesiánico) sólo puede darse como resistencia contra la retención. Lo mesiánico no existe sin su contrario porque esto mesiánico no consiste sino en un señalar los límites y el inacabamiento de aquello a cuyo poder se contrapone. Por tanto, cuando de lo mesiánico desde un punto de vista (jurídico-)político se habla, se trata de un contra-poder que no aspira a obtener poder alguno sino tan sólo a denunciar los excesos del poder.

\footnotetext{
47 Cfr. EdR, 274-276.

48 Sobre la deconstrucción rosenzweiguiana de la diferencia entre las violencias conservadora y fundadora de derecho, cfr. EdR, 394-396. Sin lugar a dudas, lo aquí señalado por Rosenzweig coincide a grandes rasgos con el ensayo benjaminiano sobre la violencia, que como La estrella vio la luz en 1921. Cfr. Benjamin, W., «Hacia una crítica de la violencia», en Obras (libro II, volumen I), trad. de J. Navarro Pérez, Abada, Madrid, 2007, pp. 183 - 206. Sobre la crítica de Rosenzweig al concepto de progreso, que por lo demás diferencia tajantemente el nuevo pensamiento rosenzweiguiano respecto de la filosofía de Hermann Cohen, cfr. EdR, 274ss. En cuanto a la influencia de Rosenzweig en el mesianismo de Benjamin, cfr. Albertini, F., «Historia, redención y mesianismo en Franz Rosenzweig y Walter Benjamin Acerca de una interpretación "política" de La Estrella de la Redención», en Á. E. Garrido Maturano (ed.), El nuevo pensamiento. Seis ensayos introductorios al pensamiento de Rosenzweig, trad. de Á. E. Garrido Maturano, Adriana Hidalgo, Buenos Aires, 2005, pp. 127-162.
} 
El progreso aparece entendido en La estrella como la postergación indefinida del final que para el adorador de esta concepción de la historia representa la meta o el fin ideal del despliegue histórico. Éste es interpretado como condición de posibilidad de realización del bien, del mismo modo que el mal y, en concreto, el mal moral, es interpretado como momento necesario de su despliegue, quedando de este modo justificado en aras de una reconciliación en curso. En una concepción de la historia como teodicea el final de los tiempos es retenido dolico-crónicamente, queda postergado sine die 49 . El místico, que permanece cerrado respecto del mundo y respecto del resto de hombres, reacciona antes esta justificación de la catástrofe a través de un permanente quietismo, como si ni el mundo ni la política existiesen, mientras que en el caso del tirano contra el que se dirige la tercera parte de La estrella ocurre exactamente lo contrario: se relaciona con el mundo como si éste hubiese encontrado ya su figura, como si se hubiese consumado. Si el místico se aleja de la política en la medida en que niega el mundo, el tirano la entiende como medio para el establecimiento de un ordenamiento definitivo del mundo que identifica (blasfemamente) con la redención. Aun estando animado por la misma fuerza mesiánica que el santo, el celo redentor del tirano carece de toda medida y, en lugar de permanecer a cada instante a la espera del final de los tiempos, termina por encontrar satisfacción en la sacralización del ídolo del Estado. En este caso el final es retenido en forma braqui-crónica, por medio de una violenta interrupción (pretendidamente) escatológica de la historia llevada a cabo a través del derecho 50 . Tanto la revolución como la contrarrevolución introducen una falsa eternidad en la historia, tratan de re-sacralizarla, sin conseguir nada más que acumular una nueva época en ella. Es por medio de la tensión entre revolución y contrarrevolución que surge la catátrofe continua en que consiste la historia o, expresado benjaminianamente, el falso estado de excepción que la concepción de la historia como progreso justifica y normaliza.

Frente a este tiempo de la historia, como contrapunto agonal suyo, o como su contra-tiempo, la temporalización del santo se da al ritmo de la temporalización del mundo y de los otros hombres, los cuales desprecia tanto el místico como el tirano. En contraposición al ser-en-el-mundo del místico, el del santo no sólo pone de manifiesto la incompletitud del mundo, sino también la determinación a la futura consumación que le es propia a pesar de que aquí y ahora pueda ser tan sólo anticipada, nunca por tanto alcanzada de manera definitiva, como sin embargo pretende el tirano ${ }^{51}$. En tanto que termporalización o anticipación del final de los tiempos, el tiempo mesiánico representa una aceleración que sin embargo persiste en su

\footnotetext{
49 Cfr. Valdecantos, A., «La demora de la ambigüedad. Notas sobre escatología, historia y ambivalencia», en J. Pardos (ed.), Historia y catástrofe, UAM Ediciones, Madrid, 2012, pp. 235-241.

50 Cfr. ibid., pp. 220-235.

51 Cfr. EdR, 321-326.
} 
carácter meramente mesiánico, no escatológico. El santo no cae en la tentación de identificarse de manera definitiva con el eschaton, no desespera y por tanto no hace la experiencia de desengaño alguno, sino que permanece en la esperanza de que el final puede siempre sobrevenir a cada instane. Convierte así el tiempo en un tiempo dispuesto para la eternidad, análogo al ho nyn kairos paulino: no detiene el tiempo escatológicamente, sino que lo interrumpe mesiánicamente; no simula final alguno, sino que permanece en el tiempo del final. Concede tiempo a un tiempo excepcional que se eleva sobre la temporalidad cotidiana sin simplemente negar este tiempo cronológico. Tampoco inaugura una nueva época del mundo, ni sobreviene como ruptura entre los dos mundos, sino como discontinuidad que no se hunde en la historia: como diferencia mesiánica que permanece como resto tanto respecto de la historia como respecto de la política, evitando así la tentación de imitar a Dios en la historia.

Esta extraordinaria temporalización, condición de posibilidad del acaecimiento de la justicia que permanece fuera de la ley, se da a través de la fiesta ${ }^{52}$. El tiempo de excepción, como tiempo dispuesto para la eternidad y, por tanto, para la justicia, se temporaliza en los días de fiesta. En ellos el ser-con-los-otros y el tener-tiempojunto-a-los-otros sólo tiene como objeto la anticipación acaeciente de la redención. En el día de excepción que anticipa la redención, el ser con los otros propio del hombre se ve transformado radicalmente: no se trata de individuos que comparten sincrónica y simultánemente un tiempo y un espacio finitos -o bien que luchan los unos contra los otros por este tiempo y este espacio finitos-, sino de una comunidad cuyos miembros se relacionan diacrónica, rítmica y recíprocamente, posibilitando la anticipación del final de los tiempos y dando de este modo tiempo -no tanto lugar- a la posibilidad de la justicia. El peligro aquí consiste en que el carácter meramente simbólico o proléptico de la fiesta y de la correspondiente comunidad sea olvidado, que ambos se conviertan en ilusión e ídolo inmanentes, mundanos, como si representasen de suyo la coincidencia de lo finito -la ley- y de lo infinito -la justicia-. En tal caso dejan de ser lo que realmente son: signo de la venida de aquello que ahora, todavía y siempre debe venir ${ }^{53}$. La diferencia entre escatología y mesianismo debe ser mantenida si se quiere evitar la violenta, fanática e idólatra divinización del mundo que el tirano lleva a cabo al (pretender) ocupar el lugar de las últimas cosas ${ }^{54}$. Rosenzweig trata de mantener esta diferencia mesiánica para hacer frente a la absolutización moderna del saeculum y evitar de este modo el des-

\footnotetext{
52 Cfr. EdR, 345ss., así como Garrido Maturano, Á. E., «Zeit als Gebet. Die phänomenologische Bedeutung der Verzeitlichung des Selbst in Franz Rosenzweigs Stern der Erlösung», en SchmiedKowarzik, W. (ed.), Der Philosoph Franz Rosenzweig, op. cit., pp. 923-938.

53 Cfr. Casper, B., Das Ereignis des Betens. Grundlinien einer Hermeneutik des religiösen Geschehens. Freiburg i. Br. - München: Karl Alber, 1993, p. 116, así como EdR, 268.

54 Cfr. Casper, B., Das Ereignis des Betens, op. cit., p. 144.
} 
gaste histórico de la correlación Dios-mundo-hombre, su absorción por parte de la cotidianidad finita. Se trata de una reorientación de esta cotidianidad que permita su apertura, más allá de un horizonte de meras posibilidades posibles, a la imprevisibilidad de lo extraordinario, al riesgo de enfrentarse a posibilidades imposibles. Sólo así será capaz de resistir a la imitación blasfema de la trascendencia y a la correspondiente irrupción del mal radical en la historia.

Roberto Navarrete Alonso

The Franz Rosenzweig Minerva Research Center

The Hebrew University of Jerusalem

roberto.navarrete.alonso@gmail.com 